Faculdade de Ciências Econômicas UFRGS

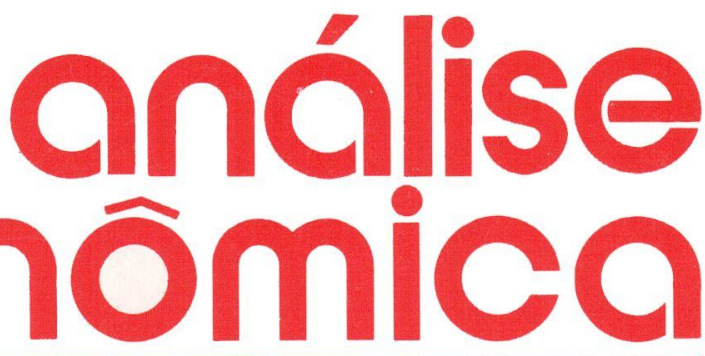

- PROgRAMA dE ESTABILIZAÇÃo DO GOVERNO COLLOR: CENTO E DEZ DIAS DEPOIS

Yeda Rorato Crusius

- SEGURO-DESEMPREGO E SUA INTEGRAÇÃO COM O SISTEMA NACIONAL DE EMPREGO José Paulo Zeetano Chahad

- RENDIMENTOS DECRESCENTES E PREÇO DO CAPITAL

Paolo Sylos Labini

- MARK-UP E DESTRUIÇÃO CRIADORA

Flávio Vasconcellos Comim

- TEORIA MONETÁRIA DE KEYNES Fernando Ferrari Filho

- ESTADO E PEQUENA PRODUÇÃO José Juliano de Carvalho Filho Ana Maria Castelo

- RACIONALIZAÇÃo DA PRODUÇÃo E ENSINO PROFISSIONAL (RS: 1889-1930) Sanara Jatahy Pesavento

- CONTRIBUICÕ̃ES À TEORIA DA LOCALIZAÇÃO INDUSTRIAL

Ruy Aguiar da Silva Leme

- POlaRizaÇÃo E deśolarizaÇÃo INDUSTRIAL NO BRASIL E NO RIO GRANDE DO SUL

Nali de Jesus de Souza
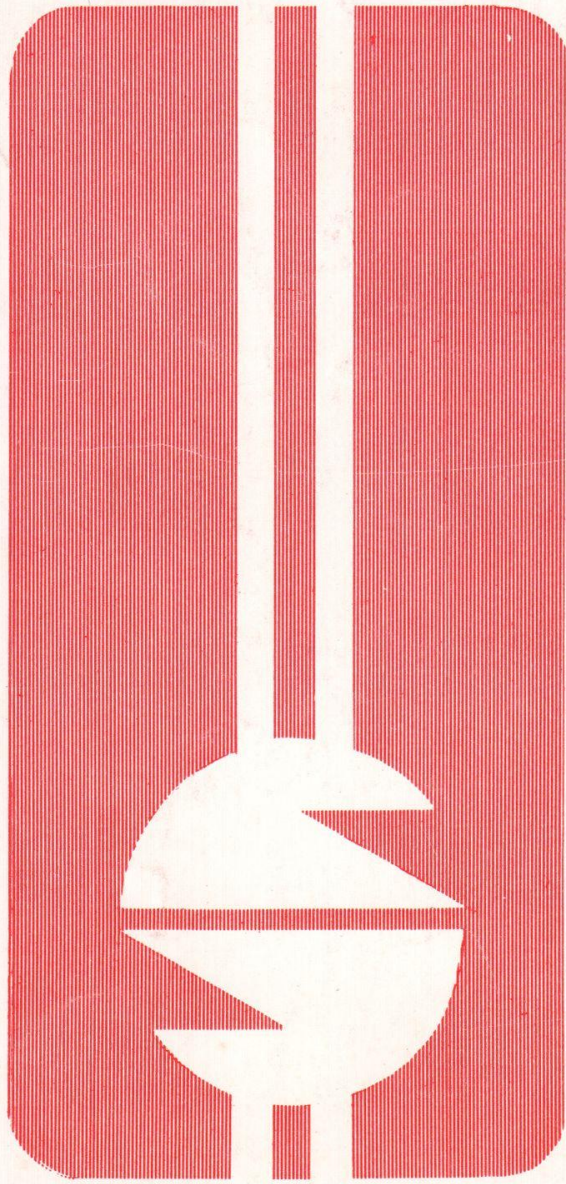
UNIVERSIDADE FEDERAL DO RIO GRANDE DO SUL

Reitor. Prof. Tuiskon Dick

FACULDADE DE CIÊNCIAS ECONÔMICAS

Diretor. Prof. Walter Meucci Nique

CENTRO DE ESTUDOS E PESQUISAS ECONÔMICAS

Diretor: Reinaldo Ignacio Adams

DEPARTAMENTO DE CIÉNCIAS ECONÔMICAS

Chefe: Prof. Pedro Cezar Dutra Fonseca

CURSO DE PÓS-GRADUAÇÃO EM ECONOMIA

Coordenador. Prof. Nali de Jesus de Souza

CURSO DE PÓS-GRADUAÇĀO EM ECONOMIA RURAL

Coordenador. Prof. Atos Freitas Grawunder

CONSELHO EDITORIAL: Achyles Barcelos da Costa, Aray Miguel Feldens, Atos Freitas Grawunder, Carlos Augusto Crusius, Ernani Hickmann, João Rogério Sanson, Juvir Luiz Mattuella, Maria Imilda da Costa e Silva, Nali de Jesus de Souza, Nuno Renan Lopes de Figueiredo Pinto, Otília Beatriz Kroeff Carrion, Otto Guilherme Konzen, Paulo Alexandre Spohr, Pedro Cezar Dutra Fonseca, Reinaldo Ignacio Adams, Roberto Camps Moraes, Valter José Stülp, Yeda Rorato Crusius, David Garlow (Wharton Econometrics Forecasts Association, E.U.A.), Edgar Augusto Lanzer (UFSC), Eleutério F.S. Prado (USP), Fernando Holanda Barbosa (FGV/RJ), Gustavo Franco (PUC/RJ), Joaquim Pinto de Andrade (UnB), Juan H. Moldau (USP), Werner Baer (Univ. de Illinois, E.U.A.).

COMISSÃO EDITORIAL: Atos Freitas Grawunder, Pedro Cezar Dutra Fonseca, Reinaldo Ignacio Adams e Roberto Camps Moraes.

EDITOR: Nali de Jesus de Souza.

SECRETARIA: Maria Ivone de Mello (normalização), Vanete Ricacheski (revisão de textos), Zélide Bregalda (Secretária).

FUNDADOR: Prot. Antônio Carlos Santos Rosa.

Os materiais publicados na revista Análise Econômica são de exclusiva responsabilidade dos autores. É permitida a reprodução total ou parcial dos trabalhos, desde que seja citada a fonte.

Aceita-se permuta com revistas congêneres. Aceitam-se, também, livros para elaboração de resenhas ou recensões.

Toda correspondência, material para publicação, assinaturas e permutas devem ser cirigidos ao seguinte destinatário:

PROF. NALI DE JESUS DE SOUZA

Revista Análise Econômica

Av. João Pessoa, 52

90.040 - PORTO ALEGRE (RS), BRASIL

Telefone: 25-58-44 ramal 33 


\title{
O SEGURO-DESEMPREGO E SUA INTEGRAÇÃO COM O SISTEMA NACIONAL DE EMPREGO: CONCEITOS E SUGESTÕES PARA O CASO BRASILEIRO*
}

\author{
José Paulo Zeetano Chahad"*
}

\section{SINOPSE}

Este texto aborda a necessidade de entrelançamento entre o programa de seguro-desemprego e o sistema nacional de emprego, tanto sob uma ótica teórica/conceitual, quanto referente ao caso brasileiro. 0 texto se fundamenta no principio de que a consolidação de ambos, seguro-desemprego e sistema nacional de emprego, somente torna-se possivel com o funcionamento conjunto.

No caso brasileiro, já existe condições para que isso venha a ocorrer, pois o programa de seguro-desemprego vem aos poucos se consolidando, e o sistema nacional de emprego, mesmo com muitos vícios e problemas de pouca eficiência, possui uma tradição de mais de 10 anos, a qual pode ser aproveitada em direção à modernização do mer-

\footnotetext{
"Extraído, com modificaçōes, do texto "O Programa de Seguro-Desemprego sob a Ótica da Intermediação da Mão-de-Obra: Teoria e Perspectivas para o Caso Brasileiro", elaborado para o projeto BRAV002/87, sob encomenda da Organização Internacional do Trabalho (OIT) e da Secretaria de Emprego e Salário do Ministério do Trabalho. O autor expressa seus agradecimentos àquelás instituiçóes pela permissão em publicar o presente texto. Agradeçe também a Nelma Ap. Santos da Cruz pela digitação final do texto.
}

** Professor Associado da FEA/USP.

ANÅLISE ECONÔMICA

\section{ANO $8 \quad$ No13}

MARÇO/90

p.43-71 
cado de trabalho. Nesse sentido, são formuladas sugestōes para a integração de ambos esses programas, o que virá ao encontro dos preceitos constitucionais hoje vigentes, e em direção ào aumento do bem-estar dos trabalhadores brasileiros.

\section{INTRODUÇÃO}

O programa de seguro-desemprego vai aos poucos se consolidando no mercado de trabalho brasileiro como um instrumento social importante numa sociedade que pretende ser moderna, justa e mais equitativa com relação aos seus trabalhadores. Com sua regulamentação, através da Lei 7798, de 11.01.90, houve uma ampliação das condiçōes de acesso do trabalhador ao recebimento de benefícios, permitindo que o seguro-desemprego caminhe mais rapidamente para sua consolidação definitiva. Esta, contudo, ainda necessita da superação de inúmeros obstáculos para que venha ocorrer, pois o seguro-desemprego não representa um simples programa de pagamento de benefícios, conforme pode ser inferido da leitura do material contido em Chahad (1987).

Os objetivos de um programa desta natureza são múltiplos, destacando-se, entre eles, a necessidade de proporcionar um verdadeiro equilibrio entre a oferta e a demanda de mão-de-obra, acabando por transformá-lo numa real formulação de política nacional de alocação de recursos humanos. Assim, todo processo de intermediação de mão-deobra acaba por ser fundamental para o seguro-desemprego, pois necessita-se, inclusive, caracterizar, com segurança, os desempregados aptos a receberem beneficios.

Desta forma, emerge, como uma associação necessária do ponto de vista operacional, o elo entre o programa de seguro-desemprego (SD) e um sistema nacional de emprego (SNE). A modernidade do mercado de trabalho requer a coexistência de ambos programas, o que é, aliás, previsto na Nova Constituição Brasileira. Eles se complementam em direção a uma melhor assistência ao mercado de trabalho, fortalecendo-o na medida em que permite até mesmo a redução dos custos do desemprego.

No caso brasileiro, já existem condições para que caminhemos nessa direção. Por um lado, o programa de seguro-desemprego vai, aos poucos, sendo regulamentando e se ampliando, Por outro, mesmo sendo objeto de inúmeras críticas, existe o sistema nacional de emprego (SINE) desde o final da década de setenta. Nesse sentido, este texto vi- 
sa aprofundar a discussão conceitual do elo existente entre o SD e o SNE, procurando destacar elementos para que se possa tornar viável a operação conjunta do seguro-desemprego e do sistema nacional de emprego, no caso brasileiro. ${ }^{1}$

Com este objetivo, o texto esta estruturado da seguinte forma: A seção seguinte traz elementos teóricos acerca da ligação entre SD e SNE, com ênfase para a questão da intermediação da mão-de-obra. A seção 3 enfoca os problemas decorrentes do funcionamento conjunto de ambos os programas. A seção 4 destaca o estágio atual da associação entre o SINE e o seguro-desemprego, enquanto a seção seguinte faz segestões para o aperfeiçoamento de seu funcionamento conjunto. Seguem considerações finais e referências bibliográficas.

\section{AS FUNÇÕES DO SISTEMA NACIONAL DE EMPREGO E O RELACIONAMENTO COM O PROGRAMA DE SEGURO- DESEMPREGO}

A revisão da experiência internacional, bem como a partir da observação do desenvolvimento histórico em nivel mundial, permite inferir que existe um forte envolvimento entre os programas de seguro-desemprego $(\mathrm{SD})$ e os serviços públicos $(\mathrm{SNE})^{2}$. Mais especificamente, o exame da bibliografia disponivel, permite inferir que, em contrapartida ao surgimento de uma legislação sobre o pagamento de benefícios aos desempregados, quase que simultaneamente surgem os SNEs, ou agências de colocação ${ }^{3}$. Isto ocorre face à necessidade de comprovar 0 status de desemprego; do fato de tentar recolocar o trabalhador $e$, até mesmo, da necessidade de pagar benefícios aos segurados. Deve-se ir além do pagamento do beneficio, recolocando o trabalhador, desde que, reconhecidamente, o emprego é mais desejável que o pagamento de benefícios, tanto para o indivíduo, quanto para a sociedade.

O Quadro 1 sintetiza as principais funções de um sistema nacional de emprego, destacando sua vinculação com o programa de seguro-de-

\footnotetext{
1 Para efeitos deste texto, SNE representa o sistema público de emprego, sob a ótica conceitual, enquanto SINE refere-se ao sistema nacional de emprego no caso brasileiro.

2 Esta resenha é apresentada no texto mencionado no primeiro rodapé. Ver ainda Blaustein $\theta$ Graig (1977); Levine (1969); OECD (1979) e ÖIT (1986).

3 Historicamente, em alguns países, o sistema nacional de emprego precedeu, na forma de "Labor Exchange", o próprio programa de seguro-desemprego. Ver Chahad (1987).
} 
semprego.

Parece claro que, em decorrência do principal elemento de envolvimento entre SD e SNE referir-se ao papel de intermediação da mãode-obra, a discussão acabe por recair, com maior ênfase, no real papel que SNE tem a desempenhar nessa função, bem como em outras atividades que acabam por correlacionar-se ao seguro-desemprego. Conseqüentemente, maior ênfase será conferida aos aspectos conceituais referentes à função de intermediação e seu relacionamento com o SD. ${ }^{4}$

\section{A intermediação da Mão-de-obra}

Parece não haver muita dúvida que os SNEs devem ser direcionados para o desempenho de inúmeras atividades voltadas para o mercado de trabalho, em particular, na tarefa de preencher vagas disponiveis, através da recolocação do trabalhador desempregado. Isto traz grandes vantagens em termos de reduçäo dos custos sociais do desemprego. Mdemais, colocar frente a frente parte dos trabalhadores desempregados com a oferia de empregos é fundamental para o sucesso do programa de seguro-desemprego e para a própria avaliação dos serviços de colocagão do SPE.

A primeira questão que se coloca é saber se esta função é a única a ser cumprida pelos SNEs, ou seja, deve ser uma atividade restrita ou ampla, desempenhada e desenvolvida conjuntamente com outras atividades? A primeira visão, que podemos classificar como estrita, argumenta que as alividades de colocação devem ser a única função do SNE. Isto aumenta sua eficiência, tornando-o mais útil ao seguro-desemprego. Alem disso, deve possuir o objetivo de apenas suplementar a busca de emprego dos trabalhadores, a qual deve ser uma atitude volintária, bem como, relativamente aos empregadores, não deve substiWuir a atividade dos mesmos em termos do que vige no sistema de livre empresa. necessiram do mercado de trabalho operando livremente para preenctier as vagas que oferecem.

Em contracartida, existem aqueles que defendem a visão integra7. deverido atuar como um mecanismo amplo em busca do equilibrio entre orerta e demande por trabalho, tanto em médio como em longo prazo.

4 O leitor deve reportar.-se ao texto que originou este artigo, já mencionado anteriormente, para uma ampla discusisián das temais funçōes do SNE e seu vínculo com o SD. 


\section{QUADRO 1 - AS FUNÇÕES DO SISTEMA NACIONAL DE EMPRE- GO SOB A ÓTICA DO SEGURO-DESEMPREGO}

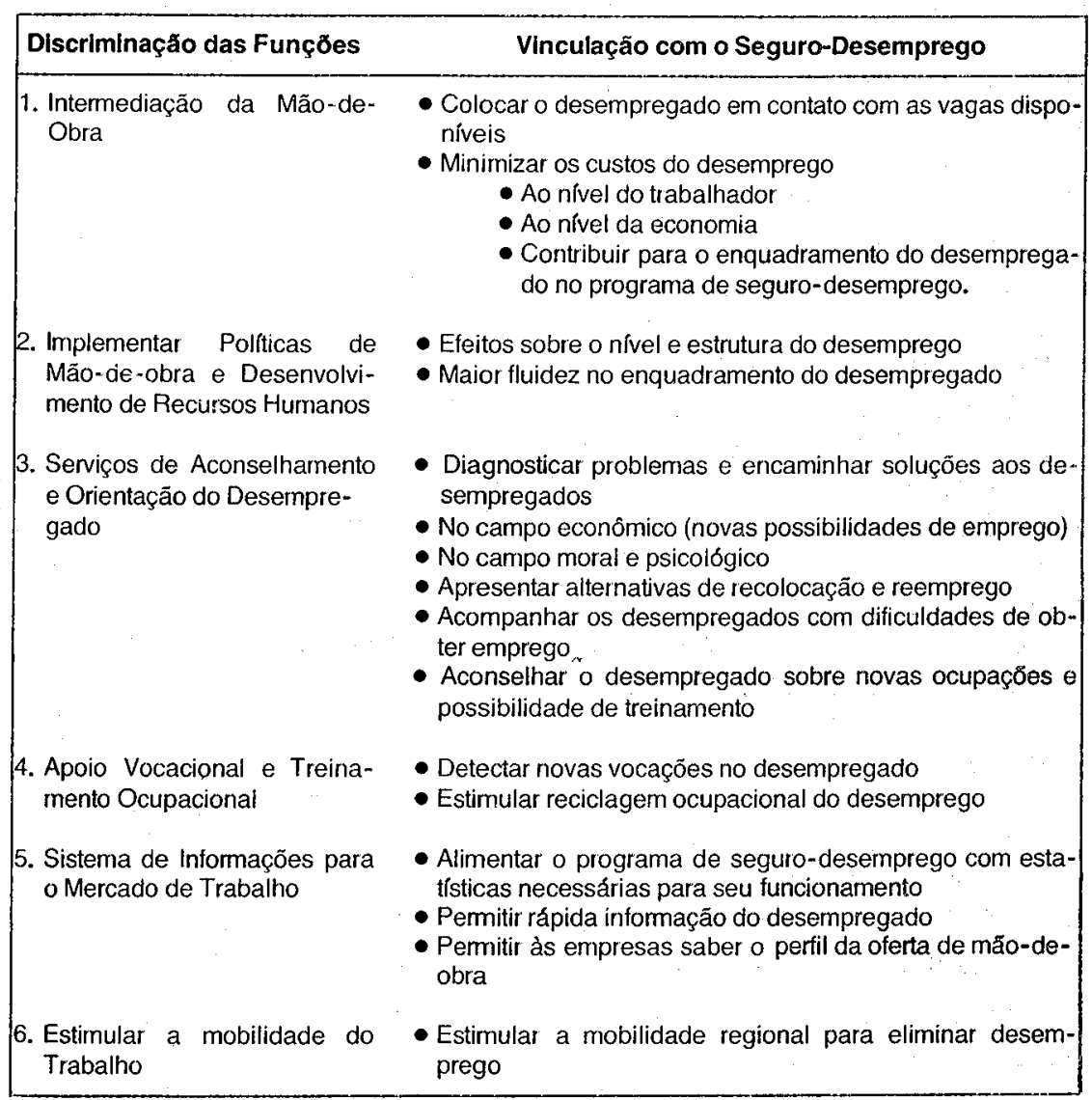

Fonte: Elaboração do autor, com base na bibliografia consultada 
Nesse caminho, o SNE deve contemplar funções como a produção de um sistema de informaçōes, de sistemas de acompanhamento de tendências da economia, de programas de aconselhamento e orientaçāo dos trabalhadores, de detecção de tendências vocacionais, de apoio a grupos de mudanças tecnológicas.

Aparentemente, tem predominado a visão integradora, com os SNEs englobando inúmeras funçōes, atuando como mecanismo fundamental em melhorar as condiçōes vigentes no mercado de trabalho. Aqui surge outra questão revelante: Devem tais serviços serem monopólios públicos?

Os defensores do monopólio público argumentam que compete ao Estado exercer controle de programas dessa natureza, incluindo determinaçöes de políticas a serem seguidas, bem como a responsabilidade pela execução de tais programas. Assim, o SNE e o SD devem sér relacionados com a responsabilidade pública que o governo possui em conduzir o mercado de trabalho a um nivet maior de bem-estar, do mesmo modo que compete ao Estado inúmeras outras atividades voltadas para esse fim, seja na área econômica, social ou cultural. Nem mesmo o reconhecimento de que atividades públicas são naturalmente ineficientes, tem abalado a crença de que tais serviços devem ser monopolizados pelo Estado. Além disso, a forma de ligação entre o SD e SNE, praticamente direciona a colocação deste último na esfera pública, visto que o seguro-desemprego compulsório é, necessariamente, algo intrinsicamente comandado pelo Estado.

Esta corrente argumenta ainda contra a própria ação privada das agências de colocação: caso esta capturem parcela do mercado de trabalho, torna-se praticamente impossível estabelecer uma atuação pública em direção do SNE. As agências privadas tendem, por um lado, a encorajar a rotatividade desnecessariamente como forma de mostrar sua eficiência e aumentar seus lucros, por outro.

Ademais, elas abusam de sua atividade como intermediária cobrando, por vezes, taxas abusivas de trabalhadores e empresas. Muitas vezes, escamoteiam as informaçōes sobre oportunidades de recolocação, criando dificuldades que "só" elas podem resolver, inviabilizando açōes no sentido da rápida adequação da oferta e demanda de trabalho, via atuação dos próprios agentes: trabalhadores e empresas. Finalmente, existe o argumento de que somente o Estado, consegue impor condições para obter as informações necessárias para o serviço de recolocação funcionar adequadamente. 
Aqueles contrários ao monopólio público, e defensores das agências privadas, argumentam que o monopólio é intrisicamente indesejado onde o princípio é de livre mercado, bem como indesejável na prática, pois acentua ineficiências estatais. Enfatizam também que existem certos segmentos do mercado de trabalho, especialmente aqueles com alta qualificação, os quais são melhor atendidos por agências privadas, pois demandam mais atençăo do que simplesmente serviços de recolocação. Isto encareceria demais os serviços, o que só poderia ser atendido pelo setor privado.

Outro aspecto diz respeito ao fato de que o Estado pode estar gastando recursos com segmentos privilegiados do mercado de trabaIho, os quais deveriam arcar com suas despesas, visto terem condições para tal. Por outro lado, se há suspeitas de ação nefasta ou desonesta das agências privadas, não se deve proibi-las, mas permitir que atuem sob licença, taxando-as, controlando-as, e deixando que o mercado resolva quem arcará com este custo.

Este último argumento parece levar ambas as correntes a um ponto comum: o comando da atividade de colocação deve pertencer ao Estado. Contudo, as agências privadas não devem ser banidas ou proibidas de atuar, ainda que, para evitar abusos e práticas não éticas, devam ser severamente controladas.

Outra questão diz respeito às possibilidades dos SNEs serem eficientes e eficazes em suas atividades de recolocação. Isto não somente do ponto de vista numérico, mas também com relação à satisfação de trabalhadores e empregadores, ao serem servidos por esses organismos.

Do ponto de vista das empresas, recai-se aqui na discussão do relacionamento que devam ter com o SNE, no que diz respeito à oferta de vagas. Estas devern ser periódicamente revistas com relação aos salários e condições de trabalho subjacentes. Ocorre que isto tem sido um ponto negativo na atividade de colocação dos SNEs, não necessariamente por vontade dos empregadores, mas devido à crescente complexidade em definir vagas a serem oferecidas, num mundo onde as rápidas transformações industriais e tecnológicas tornam rapidamente obsoletos os perfis ocupacionais existentes. Por esta razão, entre as próprias atividades dos SNEs modernos, encontram-se a detecção e a informação acerca das novas ocupações que vão surgindo.

Outro aspecto desse problema, diz respeito a saber se o envio de tais listas devam ser uma obrigação do empregador, visando fortalecer 
os SNEs. Alguns paises, como por exemplo os Estados Unidos, têm utilizado esse expediente para empresas prestando serviços ao setor público. Parece, contudo, haver oposição contra o principio da obrigatoriedade, a qual seria incompativel com um mínimo de liberdade no mercado de trabalho. Ademais, a utilidade dessa obrigatoriedade, regra geral, pode vir de forma a mascarar a verdadeira oferta de vagas disponiveis nas empresas. Isto tenderá a prejudicar os trabalhadores que estão buscando emprego via SNE. Desta forma, tem-se concluido que, em lugar da obrigatoriedade, melhor seria uma boa e completa lista de vagas, a critério das empresas.

Sob a ótica do trabalhador, algumas questōes emergem em relação ao papél de intermediação desempenhado pelo SNE. A primeira diz respeito a quem deve inscrever-se ou registrar-se nessas agências. Em princípio, deve ser condição obrigatória para aqueles solicitando beneficios e/ou recebendo ajuda pública de alguma forma. Também devem registrar-se aqueles insatisfeitos em sua ocupação atual e/ou que se considerem subempregados. Tal expediente deve ser estimulado, mas não de forma policial, ou como obrigação.

Outro aspecto diz respeito à avaliação sobre quem o coloca. A julgar pela experiência americana, parece haver uma tendência destas agências em se transformarem em instituições que não resolvam os problemas causados por trabalhadores com grandes dificuldades de serem empregados, o que os caracteriza como "desempregado" de longo prazo. Ao contrário, acabam por dedicar-se à colocação dos trabalhadores mais experimentados, e melhor qualificados, relegando a um segundo plano os trabalhadores com inúmeras dificuldades de obter emprego. Já os europeus procuram direcionar mais as atividades dessas agências para recolocação de grupos com maiores dificuldades de emprego, sem abandonar os grupos mais privilegiados.

Outro aspecto importante em avaliar a importância dos SNEs, seja do ponto de vista dessa própria instituição, seja do ponto de vista da administração do seguro-desemprego, ou mesmo do próprio funcionamento do mercado de trabalho, diz respeito à avaliação de sua eficiência na questão de intermediação da mão-de-obra. O desempenho dessas agências na atividade de pesquisa por um novo emprego, pode ser avaliado pela comparação entre os custos que representam relativamente aos beneficios que trazem. O problema é que ambas essas variáveis são de difícil mensuração, ou melhor, não podem ser atribuídos valores que estejam isentos de ambigüidades ou imune às criticas. 
Do lado dos custos, não é tarefa simples separar os custos de funcionamento dos SNEs que possam ser atribuidos somente ao atendimento aos desempregados dos demais custos. Isto porque, conforme já foi mencionado, e será ainda discutido, as agências dos SNEs, ocupamse de múltiplas atividades, sendo que as funçōes relativas ao segurodesemprego, representam apenas uma delas. Existe, pois, uma grande dificuldade de alocar corretamente os custos destinados ao funcionamento do SNE.

Ainda do lado dos custos, devem-se considerar aqueles que os trabalhadoress deva estar incorrendo na sua busca por trabalho, mesmo quando registrados no SNE devido, por exemplo, ao fato do SD e SNE estarem fisicamente separados. Nesse caso, mesmo quando registrado, o trabalhador desembolsa recursos próprios para acompanhar sua situação, verificar novas oportunidades de emprego, entrar em contato com uma firma que potencialmente pode the empregar, etc. Tais custos são praticamente impossiveis de serem calculados e, mesmo que não representem a maior parcela do total de custos, certamente são importantes para uma avaliação mais precisa dos custos efetivos dos SNEs.

Do lado da avaliação dos benefícios, a situação é também complexa. Numa visão ampla, o foco principal refere-se à redução da duração do tempo médio de desemprego, e da própria taxa de desemprego, decorrente da existência dos SNEs.

Um primeiro argumento diz respeito às dificuldades em calcular os benefícios, porque a intermediação pode estar contribuindo apenas para redistribuir a duração do desemprego entre os trabalhadores. Em outras palavras, é possivel que a redução do tempo de busca por emprego de alguns atendidos pelo SNE, represente um prolongamento do tempo de busca por trabalho de outros segmentos de desempregados, que não procuram os SNEs. Se este for o caso, é preciso saber o resultado líquido para avaliar os benefícios do SNE. Do lado da oferta de trabalho, é sempre necessário saber se houve redução líquida no tempo médio do desemprego. Já do lado da demanda, é importante avaliar se houve uma redução no tempo que uma vaga demora para ser preenchida.

Outra redistribuição que pode estar havendo é quanto ao desemprego no presente versus desemprego no futuro. $\dot{E}$ possivel que tais SNEs acabem por "forçar" o trabalhador a se engajar numa ocupação que, cedo ou tarde, ele abandonará, levando tempo até que obtenha um emprego adequado.

Neste ponto surge, inevitavelmente, a questão: supondo que não 
haja ganhos de redução do desemprego devido aos efeitos redistributivos entre grupos, é importante manter o SNE funcionando? Se os grupos beneficiados são trabalhadores desempregados com grandes dificuldades de renda e emprego no mercado de trabalho, não seria equivocada uma resposta que olhasse positivamente os SNEs, quanto à função de recolocação. Quando os prejudicados são, porém, os desempregados acima descritos, aí uma reflexão maior é necessária.

\subsection{Outras Funções dos Serviços Nacionais de Emprego}

A seção precedente abordou a função de intermediação da mãode-obra e a atividade de recolocação, certamente a mais importante no relacionamento entre o SNE e o SD. Existem, contudo, outras funções desempenhadas pelas agências oficiais de colocação, que se associam direta ou indiretamente a programa de seguro-desemprego, posto que representam atividades que atuam basicamente sobre o desemprego. Se não for este o caso, trata-se de uma função voltada para o mercado de trabalho em geral, ou para programas de formação de mão-de-obra e, por este caminho, associa-se à questão do desemprego, bem como ao pagamento de benefícios aos solicitantes.

Entende-se, porém, que embora afetem o desemprego e o programa de seguro-desemprego, possuem impactos menos diretos que a intermediação, razão pela qual não serão abordadas exaustivamente, ficando apenas seu registro no quadro 1.

\section{O FUNCIONAMENTO CONJUNTO DO SERVIÇO PÚBLICO DE EMPREGO COM O SEGURO-DESEMPREGO}

Até aqui foram apresentados, discutidos e analisados inúmeros aspectos relativos ao entrelaçamento entre seguro-desemprego e as agências oficiais de emprego, iniciando-se por aspectos conceituais e teóricos, e culminando com uma revisão sucinta sobre a visão moderna das agências de emprego. A utilidade dessas agências para o segurodesemprego, embora permaneça fora de dúvida, transparece em algumas funções dentre as várias que elas devam desempenhar.

Aborda-se agora esta interface que deve haver entre estes dois serviços de natureza oficial, procurando destacar em que condições o 
SNE pode, e deve, ser útil ao programa de seguro-desemprego. Esta seção parte do pressuposto que, mesmo na presença de problemas que possam emergir dessa associação, parece inevitável que, a partir da experiência internacional conhecida, ela deve ocorrer, seja para permitir um melhor funcionamento de ambos, seja pelo fato de fazerem parte de problemas complementares, os quais devem ser tratados conjuntamente pelo governo.

\subsection{O SNE e o SD Devem Funcionar Juntos ou Separados?}

Muito se tem discutido sobre a localização física, conjunta ou não, desses dois serviços, embora pouco registro existe na literatura consultada. Trata-se de um tópico fundamental, visto envolver aspectos relevantes do custo de financiamento de cada um desses programas.

Aqui, observam-se argumentos prós e contras, principalmente pelo fato de que existem os defensores do SNE e do SD, cada um preconizando posições isoladas. Estas posições e argumentos serão apresentados sucintamente, segundo tópicos com que surgem na literatura.

\section{a) Impactos Negativos na Imagem do SNE Devido ao SD}

Um primeiro argumento diz que, mesmo devendo atuar conjuntamente no desempenho de algumas funções, devern ser separados fisicamente, porque o seguro-desemprego acaba por prejudicar a imagem da agência de emprego, a qual passa a ser vista como um "departamento de desempregados". Isto se acentua quando se adentra por uma fase de recessão mais severa, onde os solicitantes afluem em grande número em busca dos serviços da agência, obscurecendo os outros serviços que ela deve prestar, mormente quando atuam sob a ótica da modernidade como discutida na seção 2.

A idéia de "escritório de desempregados" ganha corpo, caso a eficiência no desempenho da função de colocação seja diminuta, deixando transparecer que o SNE representa apenas um 'locus' onde os desempregados se inscrevem para algo que não se concretiza. Além disso, 0 fato de exercerem múltiplas funções como uma verdadeira agência em busca não só do equilibrio do mercado de trabaiho, mas, principalmente, no desenvolvimento dos recursos humanos, praticamente implica que o 
SNE tenha como público-alvo toda força de trabalho, enquanto os trabalhadores cobertos pelo seguro-desemprego representam apenas um segmento desta.

Existem, porém, aqueles que criticam a idéia de que o afluxo de requerentes junto ao SNE atinja negativamente a imagem deste. Isto porque, tradicionalmente, estes serviços têm devotado mais atenção a grupos específicos da força de trabalho, com dificuldades de emprego, tais como deficientes fisicos, jovens, idosos e trabalhadores de baixa qualificação, emergindo daí a dificuldade de colocação, e o conseqüente impacto negativo na imagem dessas agências.

Existem evidências de que a imagem negativa diz respeito mais ao comportamento dos empregadores do que dos trabalhadores. Estes sempre preferem contatos diretos junto às empresas, quando saem à busca de emprego, pois julgam mais eficientes como forma de rápida recolocação. Nesta ótica, dão menor importância se o SNE tem ou não imagem negativa.

Do ponto de vista dos empregadores, entretanto, advém uma forte imagem negativa quanto ao elo SNE e o SD. Existiriam duas razōes para isso, ambas fruto de informações incorretas, ou da falta de dados que afluem aos empregadores. A primeira refere-se à idéia, comum nos meios empresariais, de que a maioria dos requerentes ao seguro não faz juz ao recebimento de benefícios, utilizando os serviços de emprego para escamotear suas verdadeiras intenções. A segunda refere-se à crença, também muito difundida entre os empresários, de que todos os trabalhadores que afluem aos serviços de emprego são requerentes do seguro-desemprego.

Evidentemente, neste prisma, a separação entre os serviços de emprego e o seguro-desemprego tem recebido maior influência do setor empresarial, mesmo que, comprovadamente, tal fato não venha melhorar a imagem dos SNEs, o qual tem, historicamente, contemplado assistência a grupos menos privilegiados no mercado de trabalho.

\section{b) As Múltiplas Funções do SNE como Razão Para Separação}

Com' relação ao fato de que os SNEs têm expandido demasiadamente suas funções para justificar uma separação, existe o contra-argumento de que a principal atividade daquele serviço segue sendo, de longe, a recolocação do trabalhador desempregado, havendo a imperiosa necessidade de se aplicarem testes de habilidade para enquadrar o 
trabalhador como desempregado, somente após não haver, de fato, vaga imediatamente disponivel para ele.

Esta coordenação, indispensável entre os dois serviços, existe para assegurar a máxima exposição possível dos segurados com relação à oferta de vagas e, através disto, comprovar sua disponibilidade e desejo por trabalho. Se o SNE oferece ao solicitante um emprego adequado e o indivíduo não aceita; caracteriza-se uma prova objetiva de que não está disponivel ao trabalho. Tal atividade deve, necessariamente, ser desempenhada por autoridade pública, nesse caso o SNE. Este deve imediatamente noticiar às autoridades do seguro-desemprego quanto os resultados dos testes realizados pelo desempregado. Esta notificação é mais rápida na medida em que estes serviços atuem localmente concentrados.

Também aqui alguns buscam mostrar que o serviço de emprego não tem sido eficiente em desempenhar esta tarefa, pois consegue colocar relativamente poucos trabalhadores nas vagas ofertadas. A questão é complexa, pois nem todos os que procuram o SNE são necessariamente requerentes, assim como o problema diz respeito às falhas de atuação do serviço de emprego, o qual não consegue aplicar testes que realmente avaliem as condições efetivas dos desempregados.

\section{c) Corpo Técnico: Complementaridade ou Substituição?}

Existem, ainda, os que argumentam que a separação é necessária porque melhora a colaboração entre o pessoai dos dois organismos. Isto porque, quando estão fisicamente no mesmo local, sempre há a suposição de que existe colaboração mútua, o que não é necessariamente verdade. Mas aqui tal postura tem sido rebatida com a afirmação de que a separação tampouco garante maior colaboraçāo pela separação física desses dois serviços.

A união do seguro-desemprego com o serviço nacional de emprego existe para, supostamente, dar maior flexibilidade operacional aos dois sitemas, principalmente pela atuação conjunta do corpo técnico de cada um. Ocorre, contudo, a reclamação dos responsáveis pelo SNE, que notam um desvio das atribuições de seu pessoal quando a economia entra em recessão mais profunda. Isto porque, neste caso, a oferta de vagas declina com a retração da atividade econômica, aumentando, por outro lado, o número de requerentes ao pagamento de benefi- 
sios. Passa a haver, aparentemente, um desequilíbrio de atividades entre o corpo técnico de cada serviço. Nesse caso, o pessoal do SNE deve ir em socorro do SD, desempenhando tarefas referentes a atividades de solicitação de benefícios.

Esta possibilidade tem sido muito criticada pelos responsáveis pelo SNE. Seu argumento é que, de fato, ocorre é uma redução quantitativa em seus serviços, pela redução do número de vagas, mas um aumento da qualidade requerida nos serviços de recolocação face à retratação da demanda agregada e, conseqüente, redução das vagas em disponibilidade. Nesse sentido, em períodos de forte desemprego é mais importante ao corpo técnico do SNE permanecer no desempenho de suas funçōes tradicionais. Com este procedimento, pode dedicar-se mais intensivamente à apreciação das vagas oferecidas, bem como aplicar testes mais aprimorados de habilidade no trabalhador, e prestar informações precisas sobre o real enquadramento do trabalhador para 0 pagamento de beneficios e/ou não inclusão no seguro-desemprego.

Uma forma sugerida, para contornar esta disputa, tem sido o procedimento de contratar pessoal temporário para auxiliar no maior volume de trabalho decorrente da maior demanda por benefícios. Este pessoal adicional pode, inclusive, ser recrutado dentre aqueles requerendo benefícios, sujeitos a rápido treinamento, ou então, selecionados por algum processo de similaridade de tarefa no setor privado.

Mas aqui recai-se em outro tópico muito discutido, e apontado como forte indutor à separação física dos dois programas: a especialização cada vez maior que se tem observado com relação ao corpo técnico do SD e do SNE. Cada trabalhador envolvido em um desses programas, tem representado um elemento cada vez mais especializado em desenvolver uma tarefa.

Do lado do seguro-desemprego, o conjunto de leis e regulamentos vai se tornando cada vez mais amplo e complexo, requerendo crescente treinamento dos técnicos envolvidos. Além disso, os procedimentos burocráticos e administrativos também se ampliam e ganham complexidade, que só podem ser absorvidos por uma dedicação crescente dos indivíduos envolvidos no programa. Ademais, o SD acaba por se vincular, direta e indiretamente, aos outros programas de bem-estar e previdência social, exigindo do seu corpo técnico conhecimentos paralelos em escala cada vez maior.

Do lado do SNE, acontece algo semelhante. As atividades aumentam e mudam constantemente seu grau de complexidade, mormente 
pelas múltiplas e crescentes funções desempenhadas por estas agências, num mercado de trabalho em constante transformação. A complexidade da estrutura organizacional e ocupacional das empresas, somente pode ser entendida por técnicos que se dedicam com afinco ao desempenho das atividades para os quais foram contratados.

Assim, do ponto de vista do seguro-desemprego, pode não ser interessante uma transferência de pessoal do SNE para socorrê-lo quando houver forte afluxo de requerentes, pois isto pode ser indesejado em termos de competição, e ineficiente em termos de resultados. Os funcionários deslocados do SNE podem ter pouco interesse em atender os solicitantes de benefícios, se eles sabem que existe oferta de vagas que eles devem analisar, caracterizando até mesmo uma duplicidade de trabalho. Além disso, face à questão da especialização já descrita, terão pouco ou nenhum interesse em aprender tecnicalidades que pouco uso farão delas posteriormente. O mesmo se aplica aos técnicos que, eventualmente, se transfiram do SD para desempenhar alguma atividade temporária no SNE.

\section{d) A Necessidade de Facilitar a Vida dos Desempregados}

Uma razão bastante forte para abrigar o SNE e o SD nas mesmas dependências é que o desempregado que pretende se habilitar ao recebimento de benefícios, ou pretende uma rápida recolocação, deve se utilizar dos serviços de ambos os programas. Face a isto, parece fora de dúvida que a atuação conjunta, no mesmo local físico, traz inúmeras vantagens ao trabalhador, em termos de poupar-lhe tempo e custos de locomoção. Ademais, torna-se possivel desenvolver uma relação mais amistosa entre o desempregado e o corpo técnico tanto do SD, quanto do serviço de emprego, com ganhos para todos os envolvidos.

Destaca-se, também, que a co-habitação desses programas permite um aprendizado conjunto dos mercados de trabalho locais, onde o indivíduo costumeiramente busca sua ocupação. Tal integração tende a ser bastante vantajosa para todos, mas, em especial, para o trabalhador que vê ampliada sua possibilidade de recolocação rápida, ou mesmo no ato de se reportar periodicamente para reavaliar seus procedimentos na busca de emprego, encontra-se com pessoas que atuam, de alguma forma, em maior comunicação, podendo mais facilmente comprovar a veracidade ou não de suas afirmações e atitudes.

Finalmente, o trabalhador pode ser prejudicado pela separação fí- 
sica na medida em que, se isto ocorrer, a circulação de documentos atestando a necessidade de enquadramento como beneficiário, ou então a possibilidade de preencher uma vaga, aumenta pela distância física entre o SNE e o SD. Pode ser que, neste meio tempo, o empregador consiga preencher a vaga por outros caminhos que não o SNE, ou 0 trabalhador tenha que, novamente, se submeter a testes porque enquanto não era enquadrado devido à circulação lenta da documentação, novas ofertas de emprego afluíram ao SNE que ele estava registrado.

Como pode ser inferido a partir do exposto, são muitos os argumentos a favor e contra o funcionamento do SNE e do SD abrigados numa mesma dependência. Ocorre, entretanto, que a julgar pela experiência observada, apesar das críticas, ambos têm funcionado no mesmo local físico, indicando que, possivelmente, os aspectos positivos acabam por suplantar os negativos, ou então porque os custos de separação não se justificam plenamente. Além disso, esta discussão não pode desconsiderar aspectos relativos à realidade de cada país, mormente com relação aos aspectos regionais e locais dos mercados de trabalho, o que não foi aqui realizado.

\subsection{A Questão do Financiamento do SNE Sob a Ótica do SD}

O financiamento desses serviços, sob inúmeros aspectos, pode ser considerado como elemento fundamental nos resultados esperados de ambos. Se um bom financiamento não garante o sucesso, certamente um sistema inadequado de financiá-los é certeza de fracasso. Além disso, indefiniçōes financeiras e/ou inadequações nas fontes de recursos podem ser utilizadas como desculpas, ou mesmo obscurecer outros aspectos negativos dos programas, funcionando estes separadamente ou em conjunto.

Mas a pergunta é relevante: Como financiar o SNE e o SD atuando conjuntamente, considerando ainda que o primeiro tem expandido sobremaneira suas atividades para além dos serviços de intermediação de mão-de-obra?

Históricamente, enquanto o papel de recolocação era praticamente o único exercido pelo SNE, com este afetando o SD, era este último que gerava todos recursos financeiros para o serviços de emprego. Este serviço tem se servido tradicionalmente dos fundos destinados ao segu- 
ro-desemprego, como meio de financiar a administração e funcionamento do SNE.

A situação muda de figura quando se consideram as múltiplas funções desempenhadas pelas agências públicas modernas. Isto porque, elas exercem funções que transcendem o aspecto unilateral de recolocação, servindo para outros própositos, até mesmo de amplitude nacional, relativos à política de emprego e treinamento da mão-de-obra. Neste prisma, ao atuarem como instituições mais amplas no desenvolvimento dos recursos humanos, tem sido argumentado que recursos financeiros não deveriam provir somente daqueles oriundos do financiamento do seguro-desemprego, mas, também, provenientes das receitas fiscais do governo.

Caso contrário, os recursos para ambos, SNE e pagamento de benefícios, serão insuficientes. Na medida em que o serviço de emprego se amplia, com a diminuição de sua participação relativa no funcionamento do seguro-desemprego, vai tornando-se cada vez mais necessário buscar-se formas adequadas de financiamento para o SNE.

Todavia a realidade política, os aspectos históricos e o próprio entrelaçamento entre SNE e SD não podem, e nem devem, ser ignorados, o que implica que o programa de seguro-desemprego deve destinar um mínino de recursos aos serviços de emprego. Ademais, conforme já discutido, inúmeras atividades desempenhadas por estes serviços, embora, aparentemente, não digam respeito aos desempregados, certamente relacionam-se ao desemprego de forma indireta e, por esta via, ao programa de seguro-desemprego. Por exemplo, "retreinar" o trabalhador pode ser fator de aumento de mobilidade e, assim, pode afetar em futuro próximo o montante de recursos destinados ao pagamento de beneficios.

De qualquer forma, parece haver um certo consenso de que, quanto mais o SNE se engaja em múltiplas tarefas, incluindo uma ampla variedade de determinados serviços intangiveis, muitos dos quais com retornos esperados a médio e longo prazos, requer a definição de uma nova forma de financiamento das agências de emprego, relativamente à tradicional função de intermediação.

A busca desse novo modelo de financiamento não é tarefa simples, principalmente quando colocada na perspectiva de que deve representar a contrapartida da alocação dos custos entre as várias funções desempenhadas pelas agências públicas de emprego. Existe uma natural dificuldade em se separar custos que podem, direta e imediata- 
mente, serem atribuídos ao vinculo entre o seguro-desemprego e o SNE dos demais custos. De qualquer forma, face a esta dificuldade, pode-se tomar como padrão os gastos com a intermediação, como atribuídos à assistência ao desemprego e, assim, atendê-los com recursos provenientes do financiamento do seguro-desemprego, sendo os demais gastos realizados com recursos fiscais do governo.

Esta expansão das responsabilidades do SNE, com maior oferta de serviços para servir o mercado de trabalho, de qualquer forma, somente pode ocorrer com maiores dispêndios de recursos públicos. Isto é, tanto mais verdade quanto maior a necessidade de possuir um corpo técnico de alta qualidade, e com forte conteúdo de treinamento profissional, ou então que tais serviços se destinem para áreas antes não cobertas como, por exemplo, a zona rural. Em contrapartida, torna-se necessária uma avaliação mais critica dos recursos a serem gastos com tal expansão, os quais devem ser mais rigorosamente examinados com relação aos fins a que se destinam.

Nesse sentido, tem sido proposto que a administração dos recursos destinados à ampliação do seguro-desemprego, faça considerações referentes às análises tipo custo/benefício decorrente desta ampliação de funções. Ou seja, deve-se demonstrar que o investimento social ou custo dos recursos, diretos e indiretos, serão compensados pelos benefícios advindos, aqui também, direta e indiretamente. Isto, contudo, requer um considerável volume de informações, algumas fora dos programas do SNE e do SD. Por outro lado, como já discutido, não é tarefa fácil isolar custos e benefícios de determinadas funções, em particular no caso da intermediação da mão-de-obra.

\section{O SISTEMA NACIONAL DE EMPREGO E O SISTEMA BRASI- LEIRO DE SEGURO-DESEMPREGO: ESTÁGIO ATUAL}

No Brasil, o atendimento do seguro-desemprego, em várias de suas etapas, tem sido realizado pelas agências do Sistema Nacional de Emprego (SINE) e pelas Delegacias Regionais do Trabalho (DRTs). ${ }^{5}$ Nesse sentido, sofre de todos os males do atual Sistema Nacional de

5 Ver, entre outros, Ministério do Trabalho (1986) e Chahad (1988b), e o Boletim Indicadores Conjunturais do Ministério do Trabalho. 
Emprego, inclusive com relação à intermediação da mão-de-obra ${ }^{6}$ Sob uma perspectiva ampla, este atendimento não está integrado com outras funções típicas de um sistema público de emprego, muitas das quais sequer existem na realidade atual do programa. Quando existem, ainda são embrionárias em seu desenvolvimento, ou incipiente em sua atuação.

Em documento produzido no final de 1988, o SINE do Ceará, apresenta uma relação de problemas oriundos da atual inadequadaçãó do sistema de atendimento aos beneficiários do seguro-desemprego, 0 que, conjuntamente com as experiências acumuladas, permite visualizar os problemas do programa. Entre estes mencionam-se:

(i) Dificuldades de identificação de informações ao nivel das empresas. Aqui destaca-se a falta de identificação correta das vagas que são oferecidas, devido à precariedade de contatos entre os postos de atendimento e o estabelecimento demandante de trabalho. Isto dificulta a tarefa de orientação profissional de treinamento ao desemprega* do buscando trabalho.

Não tem sido possível identificar empresas que praticam rotatividade em demasia, o que permitiria uma intervenção governamental mais profunda, em decorrência do impacto que este expediente traz para a intermediação e para o seguro. Ainda com relação às empresas, a precariedade do sistema tem impedido localizar aquelas que, costumeiramente, preenchem erradamente as SD's, causando, com isso, prejuizos aos trabalhadores dispensados.

(ii) Dificuldades relativas ao trabalhador: Aqui destaca-se a dificuldade de resgatar a história de vida ocupacional do indivíduo, através de contatos com o mesmo, em decorrência de sua menor freqüência, e não obrigatoriedade de afluir ao posto de atendimento. Há, também, dificuldades em uma ação mais efetiva na direção da correção dos requerimentos de seguro-desemprego antes da postagem, com a redução de custos de processamento e postagem. Finalmente, existem problemas na atual sistemática relativamente à liberação dos benefícios ao trabaIhador desempregado, concorrendo para o constante retorno dos mesmos aos postos de atendimento.

6 A esse respeito, consultar Santos, Cardoso e Sales (1987), bem como o texto que originou este artigo (Chahad, 1989). 
Isto tem sido ruim para o programa de seguro-desemprego, pois leva o programa ao descrédito, visto que, além de se sentir marginalizado pela dispensa, o trabalhador se obriga a gastos adicionais de transportes, e tem que enfrentar um corpo técnico do posto de atendimento, cada vez mais desgastado.

Ainda do ponto de vista do trabalhador, deve-se destacar que a ênfase concentra-se, basicamente, em aspectos referentes ao benefício, em particular quanto à sua liberação. Isto ocorre, porém, em função não só da falta de adequação da atual sistemática de atendimento, quando do estágio inicial do programa. Além disso, parece ser um aspecto inevitável, na medida em que a clientela atual do seguro-desemprego é constituída de trabalhadores de baixa qualificação, com dificuldades para usufruir plenamente do sistema.

Em decorrência disto, tem sido constatada uma tendência de tais trabalhadores a protelarem seu reemprego, tanto em função das dificuldades de obter ocupação condizente, quanto pela diminuta diferença entre o salário que esperam receber, e o valor atual do benefício. Isto tem-se agravado ainda mais após a Constituição de 1988, onde se determinou que nenhum benefício deve estar abaixo do salário-mínimo.

De qualquer forma, pode-se afirmar que existem mecanismos institucionais que já se constituem num processo de intermediação em nivel nacional, contendo também elementos positivos como, por exemplo, equipes de trabalho que, mesmo padecendo de melhor qualidade para as funções exigidas, possuem um mínimo de conhecimento para servir de base para implementação de um completo e integrado sistema de intermediação de mão-de-obra.

\section{SUGESTÕES PARA UMA AMPLIAÇÃO DO RELACIONAMENTO ENTRE SINE E O PROGRAMA DE SEGURO-DESEMPREGO}

Tais sugestões são realizadas no contexto da parte teórica deste texto, e tendo em vista a experiência recente do programa brasileiro de seguro, no que diz respeito à questão da intermediação, bem como à experiência do SINE.

Começando por este último aspecto, parece inquestionável que o seguro-desemprego e o SINE necessitem atuar conjuntamente, e de forma profundamente integrada, não só no elemento que mais os une, ou seja, a intermediação da mão-de-obra, quanto com relação às de- 
mais atividades que complementam um sistema nacional de emprego, nos moldes já descritos. Uma possivel forma de integração aparece no diagrama 1 ao final do texto.

Grande parte do relativo insucesso do SINE ocorreu na ausência de um sistema de pagamento de beneficios aos desempregados, o qual Ihe daria mais legitimidade e, provavelmente, o obrigaria a critérios de atuação mais eficientes. A experiência internacional tern revelado como, num programa de seguro-desemprego, o envolvimento de ambos traz problemas, mas que, no balanço final, são superados por muitos aspectos positivos que emergem do entrelaçamento entre ambos.

O posto de atendimento deve ser o destino do desempregado, necessitando seu enquadramento no programa de seguro-desemprego. Para isso, é preciso que o sistema de emprego responsável pela oferta de vagas fique abrigado nas mesmas dependências onde funcionar o seguro-desemprego. Face à realidade brasileira, parece ser extremamente útil evitar-se uma sobrecarga de pressão aos trabalhadores, obrigancio-os a se deslocarem para lugares diferentes a fim de comprovarem o desemprego, relatarem seus esforços na busca por trabalho e, finalmente, receberem seus beneficios. Como se sabe, a grande maioria destes indivíduos são carentes em todos os seus sentidos, representando trabalhadores de pouca ou nenhuma qualificação, sofrendo o drama psicológico do desemprego e o drama real da ameaça à sua subsistência.

Ademais, observando-se a experiência recente envolvendo inúmeros órgãos públicos na análise do pedido e na concessão do benefício, tende inevitavelmente a prolongar os procedimentos administrativos normais, e a burocratizar excessivamente um direito do trabalhador. Este deve receber seu benefício com bastante brevidade. Finalmente, um contato estreito entre o desempregado e o posto de atendimento é necessário sob qualquer pressuposto, num sistema onde a concessão do seguro depende, fundamentalmente, da iniciativa das empresas, quase sempre despreparadas, quando não mal informadas ou, até mesmo, não muito bem-intencionadas com relação ao seguro-desemprego.

Assim, parece um aspecto indissossiável da modernização de ambos - programa de seguro-desemprego e SINE -, uma atuação conjunta, complementar e profundamente integrada, ern direção à consolidação de ambos como instituições absolutamente necessárias dentro do mercado de trabalho brasileiro. 
A julgar pela experiência passada e atual do SINE, as seguintes sugestōes operacionais são indispensáveis para o funcionamento conjunto daqueles sistemas:

(a) O Trabalhador, ao ser dispensado sern justa causa, deve recorrer imediatamente ao posto de atendimento.

Este procedimento permite checar inúmeros aspectos referentes à concessão do benefício. Além disso, deve-se sugerir seu retorno constante ao posto, para manter as autoridades informadas sobre seu esforço em obter emprego. Isto, de fato, ocorrerá caso o pagamento do benefício se faça pelo próprio posto de atendimento, outra característica que deve ser implementada no caso brasileiro. Este constante contato com o posto de atendimento permitirá que se evitem burlas, fraudes e procedimentos de natureza duvidosa, tanto das empresas, quanto dos empregados, na busca de uma maior credibilidade de ambos programas (SINE e seguro-desemprego). Essa obrigatoriedade de afluência ao posto de atendimento, somente será eficiente, contudo, se for complementado com uma assistência do trabalhador em termos de oferta de vagas em sua área de atuação, bem como orientação quanto ao "retreinamento" daqueles para os quais se constatem maiores dificuldades em obter nova ocupação.

Nesta sistemática, caberá ao posto de atendimento a palavra final sobre a habilitação ou não ao recebimento do benefício. Isto equivale dizer que o próprio posto de atendimento será responsável pelo parecer definitivo quanto ao direito de receber o benefício, e encarregado de pagá-lo, e suspendê-lo quando assim for exigido.

\section{(b) Cadastramento obrigatório de todo trabalhador dispensado sem justa causa}

Este procedimento facilitaria a tarefa de intermediação de mão-deobra, pois possibilitaria que a recolocação e a reciclagem se concentrem no conhecimento da realidade formada internamente ao próprio posto de atendimento, e não mais fundamentada na realização de relatórios sobre a atividade dos segurados, conforme determina o modelo atual.

Este cadastramento permite armazenar uma série considerável de 
informaçōes sócio-econômicas e de história de vida ocupacional-profissional do trabalhador, facilitando a tarefa de recolocação e orientação quanto ao treinamento. Isto facilita também o processo de avaliação da busca adequada por trabalho, e o julgamento de uma eventual recusa por trabalho do requerente.

Assim, parece claro o direcionamento a ser conferido ao problema da intermediação da mão-de-obra no contexto do programa de segurodesemprego numa forte integração deste com o sistema nacional de emprego. Três pontos devem ainda ser destacados em busca de um novo modelo.

O primeiro diz respeito à necessidade de se aprimorarem os recursos humanos absorvidos pelos programas SINE e seguro-desemprego. $\mathrm{Em}$ todo material analítico produzido para avaliar o SINE, parece evidente que uma de suas maiores dificuldades foi, e tem sido, a carência de mão-de-obra, tanto quantitativamente, quanto, principalmente, em termos de qualidade. Esta necessidade de investir em mão-de-obra qualificada se acentua numa integração dos dois programas, na medida em que, conforme foi destacado no inicio deste texto, ocorre uma crescente complexidade dos serviços públicos de emprego e do seguro-desemprego.

No que diz respeito à intermediação e ao atendimento do desempregado, é necessária a constante atualização do funcionário do posto de atendimento, de modo a garantir um padrão minimo de eficiência do processo. $O$ indivíduo encarregado da tarefa de recolocação deve ser um hábil entrevistador, e não um funcionário burocrático qualquer, como tem sido a praxe no modelo atual.

Em segundo lugar, numa economia que, mesmo lentamente, se moderniza, e num mercado de trabalho que, paulatinamente, se assalaria, tornando mais complexa as funçōes de um sistema de emprego, e de um programa de seguro-desemprego, parece absolutamente imprescindivel um rápido e eficiente processo de informatizaçāo, e complementaridade de todos os procedimentos destes programas. Sem isto, o fracassó é previsivel, ocorrendo tão rapidamente quanto for a dificuldade de se tornar todo sisterna informatizado.

Finalmente, é necessário destacar que a experiência mostra que o SINE e o seguro-desemprego, além de serem complementares, são sistemas federalizados. Nesse sentido, sem que se perca esta dimensão, deve-se destacar que somente se consolidarão, na medida em que forem estrategicamente traçados, de modo a conseguirem operar em ba- 
ses estaduais, ou seja, na medida em que, do ponto de vista filosófico e operacional, consigam atuar descentralizadamente, com forte apoio estadual.

Adotados estes procedimentos, os ganhos de uma forte intermediação podem ser convertidos em redução nos gastos com benefícios, contribuindo, neste estágio de implantação, para a consolidação de um modelo integrado que culmine com uma maior credibilidade do segurodesemprego e do SINE. Ocorre, contudo, que as modificações são profundas para que dependamos de ganhos internos ao próprio sistema. Parece claro, neste sentido, que acoplar um programa de seguro-desemprego a uma política de emprego, depende da destinação de recursos fiscais, visto que se trata de uma mudança estrutural no mercado de trabalho, justificando uma realocação de recursos na esfera federal. Com este tipo de gasto, a sociedade esta sempre disposta a arcar. Resta escolher a ocasião.

\section{CONSIDERAÇÕES FINAIS}

No atual momento histórico do país, particularmente com relação ao mercado de trabalho, parece não haver dúvida sobre a necessidade de se fortalecer o sistema nacional de emprego (SINE), e integrar, de uma forma bastante sólida, o programa de seguro-desemprego àquele sistema. A oportunidade é rara, pois, por um lado, o seguro-desemprego é relativamente novo, acumulando poucos vícios e necessitando avidamente de uma complementação no que diz respeito à intermediação da mão-de-obra. Por outro, a recém-promulgada Constituição estabelece novos rumos para a reformulação do sitema nacional de emprego, com destaque, inclusive para o seguro-desemprego. Existe, desta forma, uma necessidade de se avançar na integração dos dois, bem como observase um contexto aparentemente favorável para que isso venha ocorrer.

Outro aspecto a ser reforçado refere-se à formulação de um novo sistema, agora acoplado a um programa de seguro-desemprego, aproveitando-se a infra-estrutura do antigo SINE. Num pais carente de recursos, onde a experiência é importante, seria um luxo recomeçar tudo de novo, desprezando-se equipes inteiras de técnicos, alguns despreparados é verdade, mas muitas constituindo-se numa base sólida para se iniciar um processo rápido de dinamização do sistema, facilitando a integração do programa de emprego ao seguro-desemprego. 
A composição da clientela tem sido outro argumento a atormentar a mente daqueles preocupados com a temática aqui apresentada. Destaca-se, neste caso, os problemas decorrentes da realidade do mercado de trabalho dos paises em desenvolvimento, com grande predominância na informalidade das relações de trabalho. Tal diversidade de ocupações seria então um problema sério, tanto ao seguro-desemprego quanto ao SINE, que ficam inviabilizados face a uma demanda que, na verdade, não pode ser adequadamente atendida. Não se nega que a existência de relações informais de trabalho pode tornar mais árduo o desempenho das atividades destes programas, mas questiona-se se eles ficariam inviáveis.

Em primeiro lugar, porque o setor informal pode receber, como tern recebido em bases estaduais, alguma assistência do sistema nacional de emprego, conforme fazem inúmeros países. Em segundo lugar, porque a visão deve ser de longo prazo, onde o setor informal terá uma dimensāo menor, embora dificilmente desaparecerá. Em terceiro lugar, o Brasil já conta com uma força de trabalho em zonas urbanas, que redunda num mercado de trabalho bastante amplo, funcionando em moldes assalariados. Este mercado requer, e precisa, de instrumentos que organizem e disciplinem, como são o seguro-desemprego e o sistema nacional de emprego, este com múltiplas funções.

Aqui emerge outra questão basilar, referente à ação do Estado em direção àquela organização. Dois fatos justificam essa necessidade de intervenção. Um conceitual, e que diz pertencer ao Estado esta tarefa, pois somente ele possui a força de coerção para isto, além de deter os sistemas de informações para tal. O segundo, refere-se à realidade brasileira, onde a tradição de atuação do Estado é forte, em todas as esferas econômicas e sociais. Não se quer dizer com isto que a intervenção deve ser total no mercado de trabalho, mas que prescindir do papel do Estado neste país é utópico. Aquilo que deve ocorrer para que essa intervenção não se transforme em problemas não desejados, é o desenvolvimento de mecanismos de controle pela sociedade, diretamente, ou mesmo indiretamente, via poder legislativo.

Ainda nesta discussão, deve-se recordar aquilo que se disse várias vezes ao longo do texto. Ou seja, que a clientela desses programas é de baixa qualificação, representando segmentos carentes, vulneráveis e desprotegidos, cabendo ao poder constituido assisti-los. Não se trata de uma visão marcada por argumento caritativo, mas sim um posicionamento coerente com a ação do Estado capitalista, voltado para a for- 
mulação de políticas sociais.

Nesta perspectiva, é preciso reforçar a tese de que um programa integrado entre seguro-desemprego e SINE não dispensa uma complementação do ponto de vista social. Em outras palavras, a atividade de intermediação não deve se pautar somente pelo reemprego do trabaIhador, mas sim por assisti-lo nas várias necessidades que o desempregado tem ao ser colocado em disponibilidade.

Finalmente, é preciso reforçar a questão do financiameñto e equilibrio orçamentário referente ao seguro-desemprego e ao sistema nacional de emprego. Não representa uma questão simples, mas deve-se ter em mente que é praticamente impossivel discutir-se modificações estruturais que não impliquem novos custos para a sociedade. Neste caso específico, está claro que um programa eficiente de intermediação traz ganhos de recursos na medida em que pode diminuir a taxa de desemprego e, conseqüentemente, os gastos com benefícios. $\dot{E}$ difícil saber, contudo, se isso será suficiente para cobrir os custos de uma atividade moderna de intermediação.

Como palavra final fica a sugestão de que as autoridades responsáveis pelos temas trabalhistas no País devem insistir numa ação em direção ao fortalecimento do seguro-desemprego, via melhoria da intermediação de mão-de-obra, fruto de reflexão neste texto. Isto deve ocorrer mesmo com a posição que passa advir de setores que há bem pouco tempo se opunham até mesmo ao seguro-desemprego como um direito do trabalhador brasileiro. Hoje, entretanto, esse problema é uma realidade, e sua consolidação depende muito do equacionamento da questão referente à intermediação da mão-de-obra. Este é o próximo passo a ser dado.

\section{BIBLIOGRAFIA}

AMARO, M. N. L. \& COSTA, C. E. L. Seguro-Desemprego: Algumas Considerações Sobre o Programa. Brasilia, SES/MTb, 1986.

BAKKE, E. W. Public Employment Officies and Unemployment Insurance Systems: Some Hazards in Their Association, Employment Service News. Washington, DC, 1935.

BLAUSTEIN, S. J. Unemployment Insurance Objetives and Issues: An Agenda for Research and Evolution. Kalamazoo, The W. E. Upjohn Institute for Employment Research, 1968. 
Some New Directions. Kalamazoo, The W. E. Upjohn Institute for Employment Research, 1981.

BLAUSTEIN, S. J. \& CRAIG, I. An International Review of Unemployment Research. Kalamazoo, The W. E. Upjhon Intitute for Employment Research, 1977.

CARVALHO, E. A. \& COLARES, J. T. Intermediação de Mão-de-Obra e Seguro-Desemprego: A Necessidade de Interação. Boletim de Análise do Mercado de Trabalho. Fortaleza, SINE-CE, jan_jun., 1989.

CHAHAD, José P. Z. O Programa de Seguro-Desemprego sob a Ótica de Intermediaçāo da Mão-de-Obra: Teoria e Perspectivas para o Caso Brasileiro. Brasília, Relatório de Pesquisa elaborado para a SES/MTb e para a OIT, 1989.

. Seguro-Desemprego e a Organização do Mercado de Trabalho: O Papel da Intermediação da Mão-de-Obra. Florianópolis, set. 1988a, mímeo preparado para III ENSINE.

sileiro com Ênfase na Questāo do Financiamento. São Paulo, Relatório de Pesquisa, Programa FIPE/SEPLAN-PR, 1988b. Teóricos e Perspectivas para o Brasil. São Paulo, IPE/USP, 1987 (Ensaios Econômicos, nº 64).

. O Seguro-Desemprego no Cenário Internacional. São Paulo, IPE/USP, 1984, (Relatório de Pesquisa nº 19).

KITSON, H. D. \& NEWTON, J. B. Helping People Find Jobs, How to Operate a Placement Office, New York, Harper e Brothers, 1950.

LEVINE, L. The Role of Unemployment Insurance in National Manpower Policies. Kalamazoo, The W. E. Upjohn Institute for Employment Research, 1972.

. The Public Employment Service in Social and Economic Policy, Deliberations of Working Party. Paris, OECD, 1969.

MINISTÉRIO DO TRABALHO. Proposta de Organização do Sistema Nacional de Emprego. Brasília, SINE/SES/MTb, 1989. 
. Considerações Gerais sobre o Mercado de Trabalho e o Sistema Nacional de Emprego no Brasil. Brasilia, SES/ Coordenadoria de Promoção de Emprego, 1986, mímeo.

. Seminário Açōes do Ministério do Trabalho no Campo do Emprego e Funçōes do Sistema Nacional de Emprego (SINE). Brasília, 1979. (Relatório Final, Coleção Il, Emprego).

OECD. Unemployment Compensation and Related Employment Policy Measures, General Report and Country Studies. OECD, 1979.

OIT. Colóquio Internacional Sobre EI Papel y la Organization de los Serviços del Empleo. Nuremberg, 14-18 out., 1986.

. Problemas de Organización de los Serviços del Empleo en los Países Económicamente Poco Desarrollados, Revista Internacional del Trabajo. Vol. LIII, n 4, abril, 1956.

PREALC, Sistema de Información para el Analisis Del Mercado de Trabajo. Santiago do Chile, OIT/PREALC. (Documentos de Trabajo).

SANTOS, L. A.; CARDOSO, A. M. \& SALES, M.. Emprego e Pobreza no Estado de Sāo Paulo: Mecanismos Institucionais de Apoio às Politicas de Emprego no Periodo de 1974-1984. São Paulo, CEBRAP, 1987. (Relatório para a SRT/SP).

SEMO. Sistema Estadual de Mão-de-Obra e Sistema Nacional de Emprego. São Paulo, SET/MTb, SEPLAN/SP. 1976. (Documento 4).

SINE, Sistema Nacional de Emprego: Aspectos Organizacionais e Necessidades de sua Definição Institucional, maio, 1989, mimeo.

SINE-CE. Sistema Alternativo de Operacionalização do SeguroDesemprego. Fortaleza, nov. 1988.

STEVENS, D. W. Assisted Job Research for the Insured Unemployed Studies in Unemployment Insurance. Kalamazzo, The W. E. Upjohn Institute for Employmewnt Research, 1974.

YOUNG, E. B. Functional Relationship Between Employment Senice and Unemployment Compensation, Employment Service News., Washington, DC, set. 1938. 


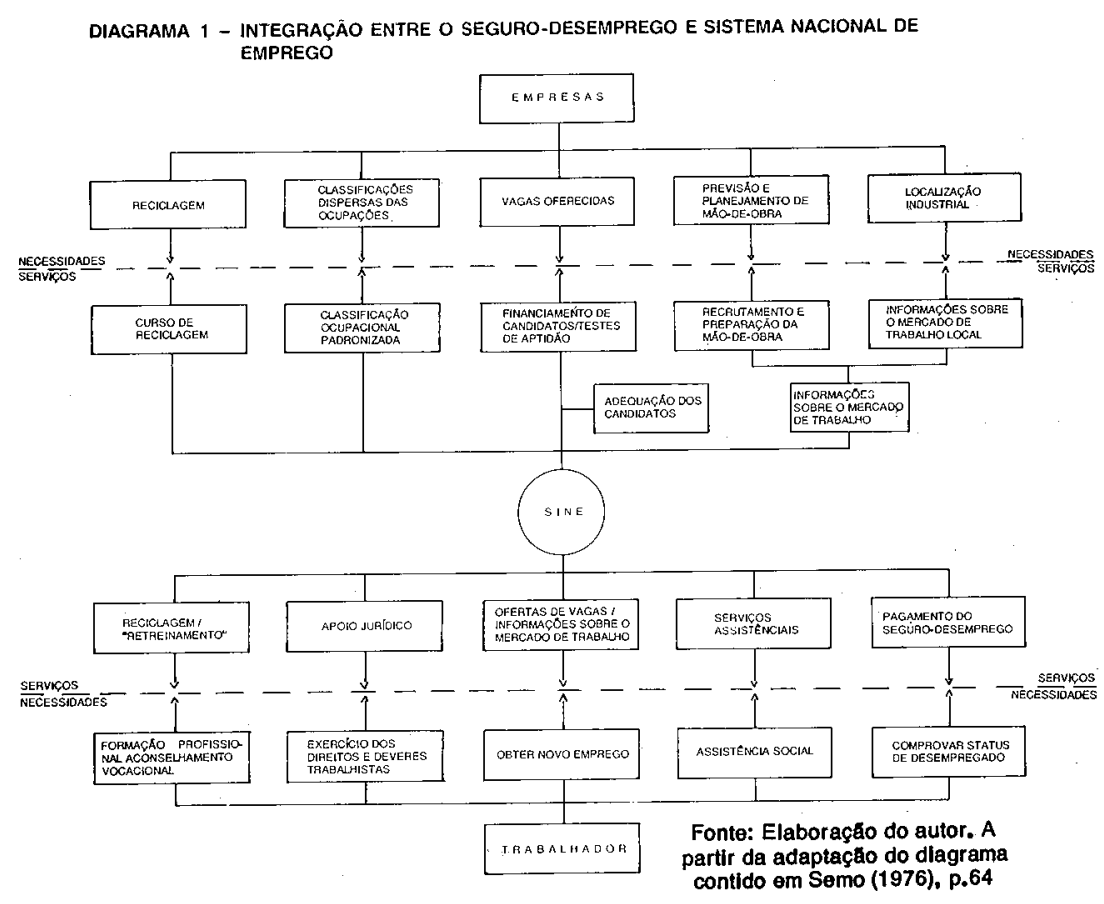

